\title{
Selective Formation of Intermetallic Compounds in Sn-20ln-0.8Cu Ball Grid Array Solder Joints with Au/Ni Surface Finishes
}

\author{
HSING-FEI WU, ${ }^{1}$ MING-JUI CHIANG, ${ }^{1}$ and TUNG-HAN CHUANG ${ }^{1,2}$ \\ 1.-Institute of Materials Science and Engineering, National Taiwan University, Taipei 106, \\ Taiwan. 2.-E-mail: tunghan@ccms.ntu.edu.tw
}

After Sn-20In-0.8Cu solder balls are reflowed on a ball grid array (BGA) substrate (substrate $\mathrm{A}$ ) with an $\mathrm{Au} / \mathrm{Ni}$ surface finish, scallop-shaped intermetallic compounds with a composition of $0.83\left[\mathrm{Cu}_{6}\left(\mathrm{Sn}_{0.87} \mathrm{In}_{0.13}\right)_{5}\right]+0.17\left[\mathrm{Ni}_{3}\left(\mathrm{Sn}_{0.87} \mathrm{In}_{0.13}\right)_{4}\right]$ are formed at the solder/pad interface. The distribution of the intermetallics is not altered by gravity or by multiple reflows of the solder joints. As another substrate (substrate B) is further attached onto the primary reflowed BGA assembly to form a sandwich structure subjected to subsequent multiple reflows, the $\mathrm{Cu}_{6}\left(\mathrm{Sn}_{0.87} \mathrm{In}_{0.13}\right)_{5}$ interfacial intermetallic scallops remain still on the side of substrate A while many $\mathrm{Au}\left(\mathrm{In}_{0.91} \mathrm{Sn}_{0.09}\right)_{2}$ intermetallics of cubic shape appear near the solder/Ni interface on the side of substrate B. When the $\mathrm{Sn}-20 \mathrm{In}-0.8 \mathrm{Cu}$ solder balls are assembled simultaneously in between two substrates (A and B), $\mathrm{Au}\left(\mathrm{In}_{0.91} \mathrm{Sn}_{0.09}\right)_{2}$ intermetallic cubes of equal proportion are observed to form on both sides of the assembly. In summarizing the results, it is proposed that the diffusion of $\mathrm{Cu}$ atoms in the $\mathrm{Sn}-20 \mathrm{In}-0.8 \mathrm{Cu}$ solder toward the Ni layers after $\mathrm{Au}$ thin-film dissolution on $\mathrm{Au} / \mathrm{Ni}$ surface finishes led to the formation of $\mathrm{Cu}_{6}\left(\mathrm{Sn}_{0.87} \mathrm{Zn}_{0.17}\right)_{5}$ intermetallic compounds, which prevailed over the gravitational effect so that no intermetallic sedimentation in the liquid solder would occur. The appearance of $\mathrm{Au}\left(\mathrm{In}_{0.91} \mathrm{Sn}_{0.09}\right)_{2}$ at the Ni/Sn-20In-0.8Cu interfaces was hindered by the preferential formation of $\mathrm{Cu}_{6}\left(\mathrm{Sn}_{0.87} \mathrm{Zn}_{0.17}\right)_{5}$ until the $\mathrm{Cu}$ atoms in the Sn-20In-0.8Cu solder matrix were consumed to a lower content via the attachment of a second substrate to the assembly.

Key words: $\mathrm{Sn}-20 \mathrm{In}-0.8 \mathrm{Cu}$, solder joints, $\mathrm{Au} / \mathrm{Ni}$ surface finishes

\section{INTRODUCTION}

The $\mathrm{Sn}-0.9 \mathrm{Cu}$ alloy is considered one of the promising $\mathrm{Pb}$-free solders for electronic packaging. ${ }^{1}$ The $\mathrm{Sn}-20 \mathrm{In}-0.8 \mathrm{Cu}$ solder has been developed from the addition of the element indium as a melting-point depressant into such an eutectic Sn-Cu alloy system. In a previous study, the intermetallic compounds formed during reflow and aging at $75^{\circ} \mathrm{C}$ and $115^{\circ} \mathrm{C}$ in a $\mathrm{Sn}-20 \mathrm{In}-0.8 \mathrm{Cu}$ ball grid array (BGA) package with $\mathrm{Au} / \mathrm{Ni} / \mathrm{Cu}$ pads are analyzed. ${ }^{2}$ Those results indicate that scallop-shaped intermetallic compounds (IM1P) of a mixed composition $0.83\left[\mathrm{Cu}_{6}\left(\mathrm{Sn}_{0.87} \mathrm{In}_{0.13}\right)_{5}\right.$

(Received October 27, 2003; accepted March 30, 2004)
$+0.17\left[\mathrm{Ni}_{3}\left(\mathrm{Sn}_{0.87} \mathrm{In}_{0.13}\right)_{4}\right]$ appear at the interfaces between reflowed $\mathrm{Sn}-20 \mathrm{In}-0.8 \mathrm{Cu}$ solder balls and $\mathrm{Au} / \mathrm{Ni} / \mathrm{Cu}$ pads. Accompanying the formation of these interfacial intermetallics, a significant amount of $\left(\mathrm{Au}_{0.80} \mathrm{Cu}_{0.20}\right)\left(\mathrm{In}_{0.33} \mathrm{Sn}_{0.67}\right)_{2}$ intermetallic compounds (IM2P) can be found in the solder matrix.

When the Sn-20In-0.8Cu BGA package is assembled on a printed circuit board with $\mathrm{Au} / \mathrm{Ni} / \mathrm{Cu}$ pads similar to those at the package level, the IM1P and IM2P intermetallic compounds are found to form selectively at the top and bottom interfaces of the sandwiched solder joints, respectively. This phenomenon is close to the observations by Kim et al. on the asymmetric distribution of ripening $\mathrm{Cu}_{6} \mathrm{Sn}_{5}$ intermetallics in a $\mathrm{Si} / \mathrm{Sn}-37 \mathrm{~Pb}$ solder/Si sandwich structure with 
$\mathrm{Au} / \mathrm{Cu} / \mathrm{Cr}$ metallization on $\mathrm{Si}^{3}$ According to their findings, the ripening intermetallic compounds are formed preferentially at the bottom interface of the $\mathrm{Si} /$ solder/Si solder joints after 10 -min reflow time at $200^{\circ} \mathrm{C}$, and the gravity effect is suggested to account for this phenomenon. In another study by Lee et al. on the reflow characteristics of the $\mathrm{Sn}-3.5 \mathrm{Ag}$ solder dispersed with $\mathrm{Cu}$ power, ${ }^{4}$ the reacted $\mathrm{Cu}_{6} \mathrm{Sn}_{5}$ dispersoids are observed to exhibit a tendency to coarsen significantly and segregate near the solder/Cu interface after the third reflow cycle. The sedimentation of intermetallic dispersoids near the interface is also attributed to the gravity effect, as proposed by the authors. ${ }^{4}$

To understand the mechanism responsible for the selective formation of intermetallic compounds in the Sn-20In-0.8Cu BGA packaging assemblies, this study has engaged in a variety of multiple reflow processes. One of the main goals is to clarify the role of gravity in intermetallic formation for this case project.

\section{EXPERIMENTAL}

The bismaleimide-triazine resin substrates with a thickness of $0.25 \mathrm{~mm}$ were fitted with $49 \mathrm{Cu}$ pads in the same manner as a prior research. ${ }^{5}$ The $\mathrm{Cu}$ pads were electroplated with $5-\mu \mathrm{m} \mathrm{Ni}$ and $0.5-\mu \mathrm{m} \mathrm{Au}$. The $\mathrm{Sn}-20 \mathrm{In}-0.8 \mathrm{Cu}$ (wt.\%) solder balls of $0.4 \mathrm{~mm}$ in diameter were used for this study. The solidus and liquidus temperatures of this solder alloy as analyzed by differential scanning calorimetry are $168.3^{\circ} \mathrm{C}$ and $185.4^{\circ} \mathrm{C}$, respectively. Five types of the multiple reflow processes were conducted, as demonstrated by Fig. 1 .

- Type 1: After the initial (primary) reflow, the specimen along with substrate A was turned over and reflowed again (secondary) 1-5 times.

- Type 2: After the primary reflow, the specimen along with substrate A was turned over, assembled with another substrate (B), and reflowed (secondary) 1-5 times.

- Type 3: The sandwich specimen of type 2 after primary and secondary reflows was turned over and reflowed again (tertiary).

- Type 4: After the primary reflow, the specimen along with substrate A was covered by substrate $B$ (face-to-face) and then secondary reflowed.

- Type 5: Two substrates (A and B) were face-toface sandwiched with solder balls in between and reflowed 1-2 times.

The same temperature profile was employed for various types of the reflow process carried out in a hot air furnace equipped with five heating zones, as given by Fig. 2. Cross sections of the specimens were cut through one row of the solder balls and grinding and polishing were done through 1,500-grit $\mathrm{SiC}$ paper and $0.3-\mu \mathrm{m} \mathrm{Al}_{2} \mathrm{O}_{3}$ powder after various multiple reflow processes. The intermetallic compounds formed in the solder joints were then observed via scanning electron microscopy, and their chemical compositions analyzed using energy dispersive spectrometry (EDX).

\section{RESULTS AND DISCUSSION}

Figure 3 shows the intermetallic compounds formed in type 1 specimens. After primary reflow of the Sn-20In-0.8Cu BGA solder balls on $\mathrm{Au} / \mathrm{Ni} / \mathrm{Cu}$ pads, scallop-shaped intermetallics (IM1P) are found at the solder/pad interface (Fig. 3a). The composition of these interfacial intermetallics was analyzed in a prior study as a mixture of $0.83\left[\mathrm{Cu}_{6}\left(\mathrm{Sn}_{0.87} \mathrm{In}_{0.13}\right)_{5}\right]+$ $0.17\left[\mathrm{Ni}_{3}\left(\mathrm{Sn}_{0.87} \mathrm{In}_{0.13}\right)_{4}\right]$. In addition, intermetallic dispersoids (IM2P) in large quantities with a composition of $\left(\mathrm{Au}_{0.80} \mathrm{Cu}_{0.20}\right)\left(\mathrm{In}_{0.33} \mathrm{Sn}_{0.67}\right)_{2}$ also appear in the solder matrix. The formation of such an $\mathrm{AuIn}_{2}$ phase has been reported for the cases of solid/solid ${ }^{6}$ and liquid/solid ${ }^{7}$ interfacial reactions of In solders with Au substrates. As indicated by Fig. 3b-f, there is no change observed in the distribution of IM1P and IM2P intermetallic compounds when the primary specimens are turned over and the face-down solder balls are multiple reflowed. Although the IM2P intermetallic phase has a density $\left(9.71 \mathrm{~g} / \mathrm{cm}^{3}\right) \mathrm{much}$ higher than that for the liquid solder $\left(7.3 \mathrm{~g} / \mathrm{cm}^{3}\right)$, the gravitational sedimentation of these particles, as observed by Lee et al. ${ }^{4}$ for the $\mathrm{Cu}_{6} \mathrm{Sn}_{5}$ dispersoids in the Sn-3.5Ag solder, does not occur in this case nor have the $\left(\mathrm{Au}_{0.80} \mathrm{Cu}_{0.20}\right)\left(\mathrm{In}_{0.33} \mathrm{Sn}_{0.67}\right)_{2}$ intermetallics coarsened after a five-time multi-reflow cycle (Fig. 3). This also conflicts with the result of Lee et al. that the $\mathrm{Cu}_{6} \mathrm{Sn}_{5}$ dispersoids in the Sn$3.5 \mathrm{Ag}$ solder have coarsened significantly after a three-time reflow cycle. ${ }^{4}$ However, Fig. 3 shows that the IM1P intermetallic scallops have been growing with the increase in reflow cycles. The thickness that the IM1P intermetallics have grown to after primary and multiple reflows is plotted in Fig. 4 versus the corresponding number of reflow cycles, which shows a parabolic growth relation. Yet, the shear strengths of the Sn-20In-0.8Cu solder joints for these specimens have almost remained constant after multiple reflows, as measured in Fig. 5.

The intermetallic compounds formed in the Sn20In-0.8Cu BGA solder joints after the type 2 reflow process are shown in Fig. 6. The scallop-shaped IM1 intermetallic compounds appear at the solder/pad interface of the primary reflowed substrate A while many intermetallic particles (IM2) of cubic shape selectively form on the opposite substrate B of the sandwich specimen. There has been a similar appearance of the cubic-shaped intermetallics during the soldering reaction of In49Sn solder in BGA packaging with the $\mathrm{Au} / \mathrm{Ni}$ surface finish. ${ }^{5}$ The composition (at.\%) of the IM1 intermetallics is $\mathrm{Cu}: \mathrm{Ni}: \mathrm{Sn}: \mathrm{In}=$ 32.59:17.84:43.47:6.10, corresponding to the mixture of $0.65\left[\mathrm{Cu}_{6}\left(\mathrm{Sn}_{0.87} \mathrm{In}_{0.13}\right)_{5}\right]+0.35\left[\mathrm{Ni}_{3}\left(\mathrm{Sn}_{0.87} \mathrm{In}_{0.13}\right)_{4}\right]$. The IM1P intermetallics formed after primary reflow are of a similar composition, but their compositional ratio of $\mathrm{Cu}_{6}\left(\mathrm{Sn}_{0.87} \mathrm{In}_{0.13}\right)_{5}$ to $\mathrm{Ni}_{3}\left(\mathrm{Sn}_{0.87} \mathrm{In}_{0.13}\right)_{4}$ is different from that for IM1. The EDX analysis also gives the composition of the cubic-shaped IM2 
Type1 :
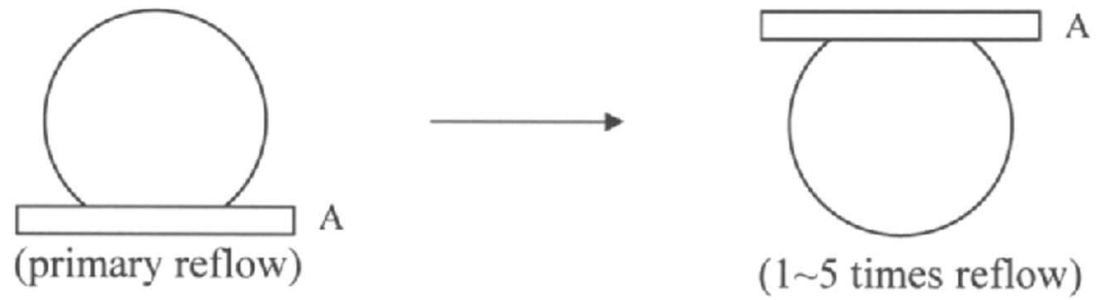

Type 2:
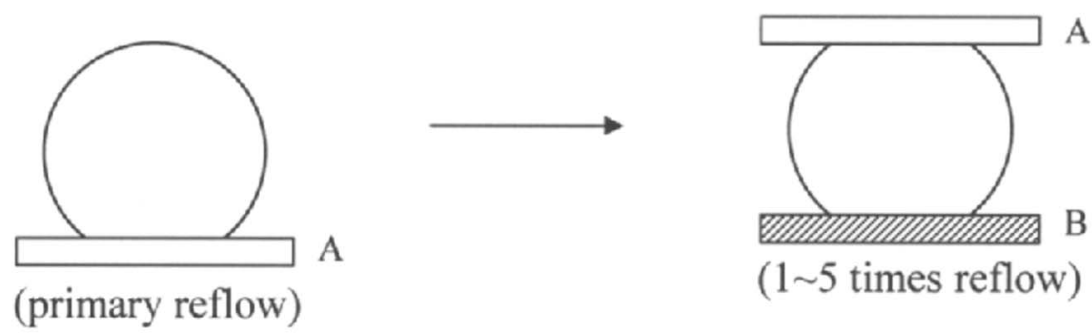

(1 5 times reflow)

Type 3:

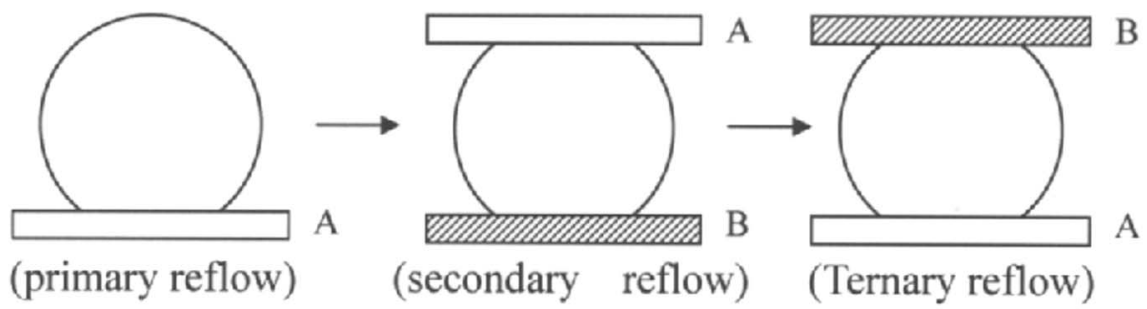

Type 4:
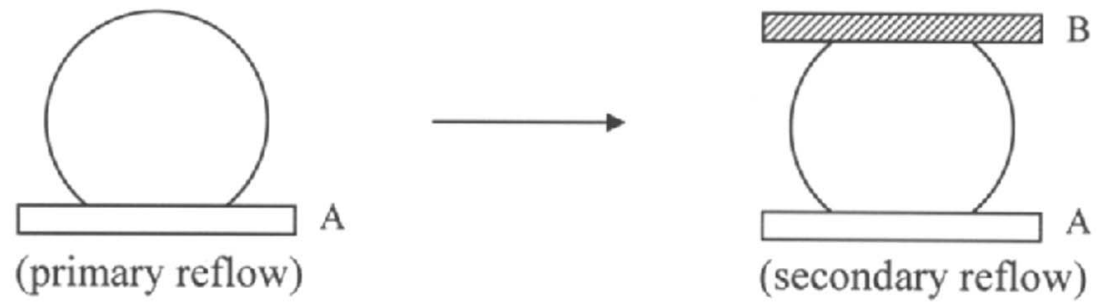

Type 5:
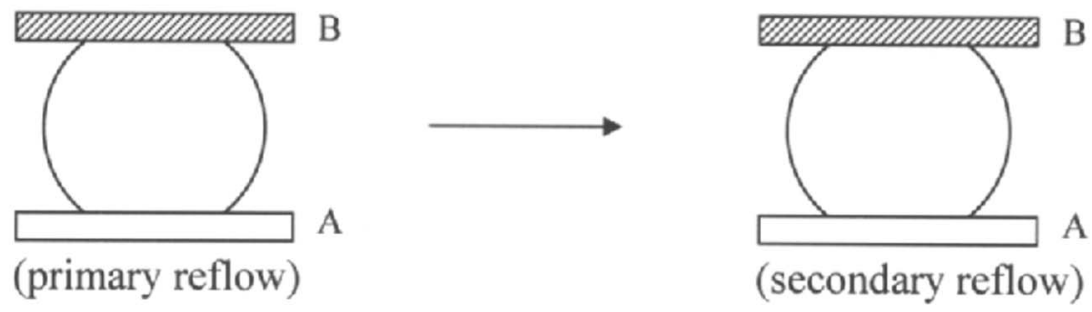

Fig. 1. Various types of the multiple reflow processes in this study.

intermetallics as $\mathrm{Au}\left(\mathrm{In}_{0.91} \mathrm{Sn}_{0.09}\right)_{2}$. Note that $\mathrm{Cu}$ is absent here, and this composition deviates somewhat from the primary reflowed IM2P intermetallics. Figure 7 shows that the IM1 intermetallic scallops at the top interface grow increasingly with the increase of type 2 reflow cycles from 1 to 5 times. Moreover, the cubic-shaped IM2 intermetallics on the bottom substrate have coarsened significantly and tend to float away. Accompanied with the upward floating of the coarsened IM2 intermetallic cubes, an intermetallic layer with a composition similar to that of IM1 appears on the Ni layer of the bottom substrate 


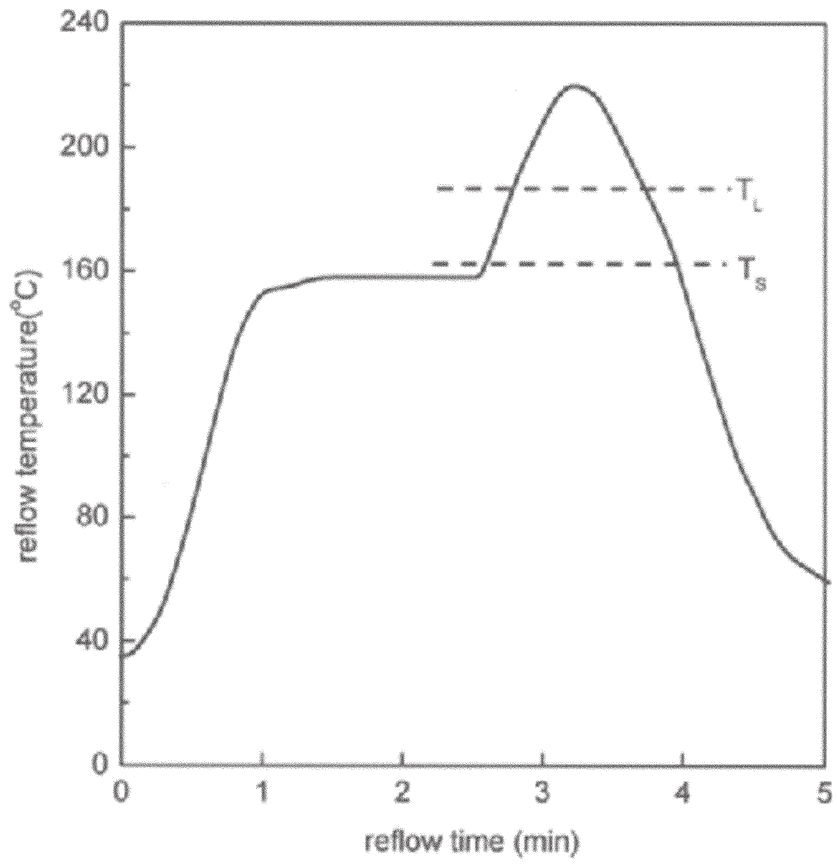

Fig. 2. Temperature profile for multiple reflowing of the Sn-20ln$0.8 \mathrm{Cu}$ solder in BGA packages used in this study $\left(T_{S}\right.$ : solidus, and $\mathrm{T}_{\mathrm{L}}$ : liquidus of the solder).

(Fig. 7c). The formation of such an IM1 intermetallic layer can repel the coarsened IM2 intermetallic cubes. The result can be used to explain the absence of such IM3 intermetallic cubes at the top interface of the sandwiched solder joint following a type 2 multiple reflow process.

The sandwich specimen of type 2 after primary and secondary reflows (Fig. 6) is turned over and tertiary reflowed (type 3 process), which results in the forma- tion of the intermetallic compounds shown in Fig. 8. The intermetallic scallops (IM1) and cubic-shaped intermetallics (IM2) formed after primary and secondary reflows have stayed unchanged on their respective sides of substrates A and B. Turning over and tertiary reflowing of the sandwich specimen does not alter the selective distribution of the intermetallic compounds on respective substrates manifested after the type 2 reflow process. The type 4 reflow process provides a similar result, as shown in Fig. 9, where the IM1 intermetallic compounds linger on the side of primary reflowed substrate A while the cubic-shaped IM2 intermetallics selectively form at the interface of the secondary reflowed substrate B. In both cases, the existence of the cubic-shaped intermetallics (IM2) with higher density at the top interface offsets the gravitational effect on intermetallic distribution.

As Fig. 10 shows, the cubic-shaped IM2 intermetallics near both the top and bottom substrates are formed in a similar manner after simultaneous reflowing of the BGA solder joints in between two substrates (A and B) as a sandwich structure (type 3 process). Two times reflowing will lead to the coarsening of the cubic-shaped IM2 intermetallics (Fig. 11). Similar to the observation in Fig. 7c, the cubic-shaped IM2 intermetallics also tend to float away from the substrates because of the formation of an IM1 intermetallic layer on the $\mathrm{Ni} / \mathrm{Cu}$ pad. This phenomenon becomes more obvious with the coarsening of the IM2 intermetallics induced by 2 times reflow. Figures $10 \mathrm{~b}$ and $11 \mathrm{~b}$ show that the number of IM2P intermetallic dispersoids formed in the solder matrix is much smaller when compared with what occurs after the primary reflow and multiple reflow processes to type 1 and type 2 specimens (Figs. 3 and 6 ).
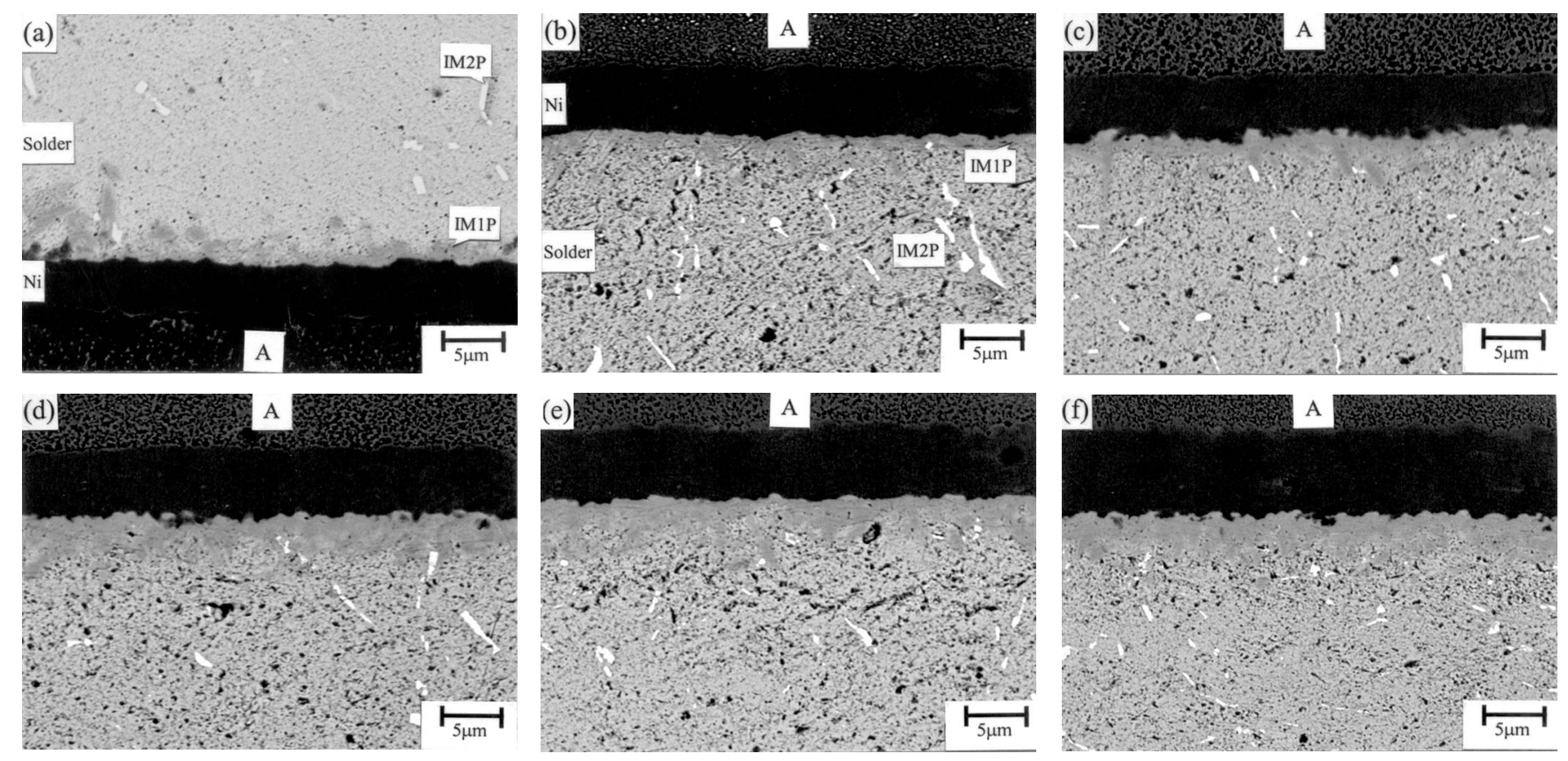

Fig. 3. Intermetallic compounds formed after primary and type 1 reflow processes: (a) primary reflow and (b)-(f) turning over the primary specimen and multi-reflowing for 1-5 times, respectively. 


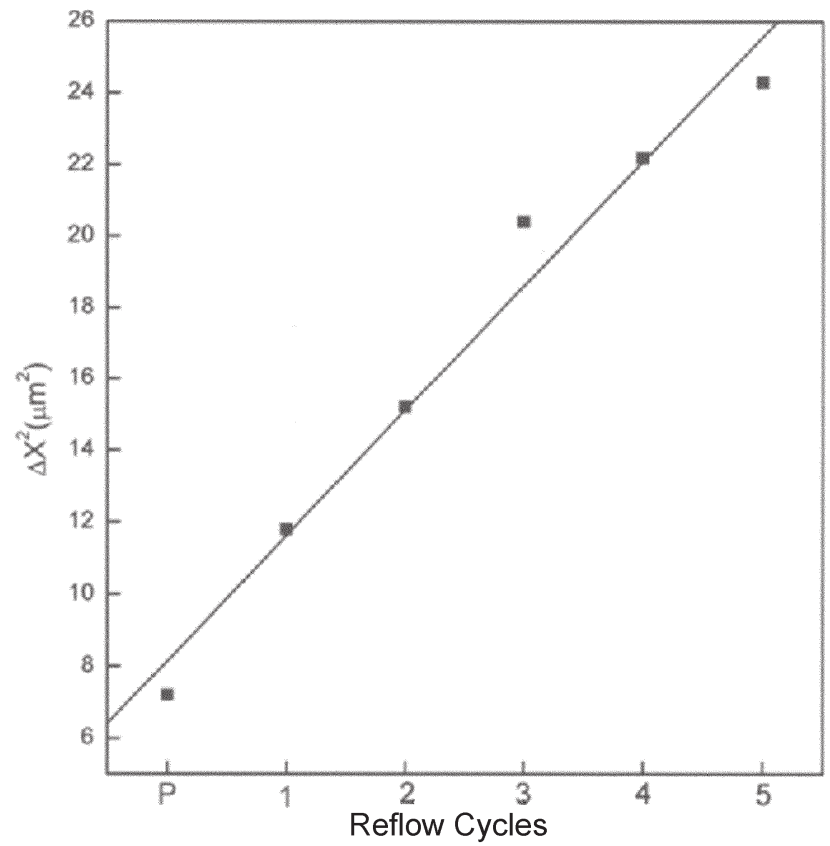

Fig. 4. Square root of the thickness $(\Delta x)$ of IM1P intermetallic compounds formed at the interfaces between $\mathrm{Sn}-20 \mathrm{In}-0.8 \mathrm{Cu}$ solder balls and $\mathrm{Au} / \mathrm{Ni}$ surface finishes after multi-cycle reflowing.

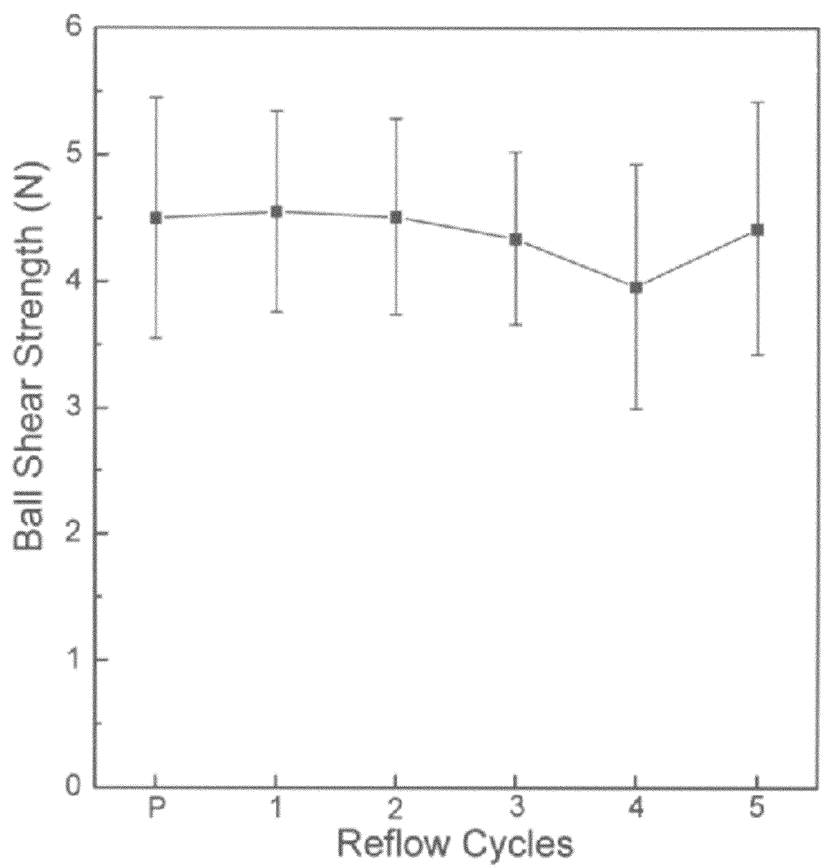

Fig. 5. Ball shear strengths of the $\mathrm{Sn}-20 \mathrm{ln}-0.8 \mathrm{Cu}$ solder in BGA packaging with $\mathrm{Au} / \mathrm{Ni}$ surface finishes after multi-cycle reflowing.
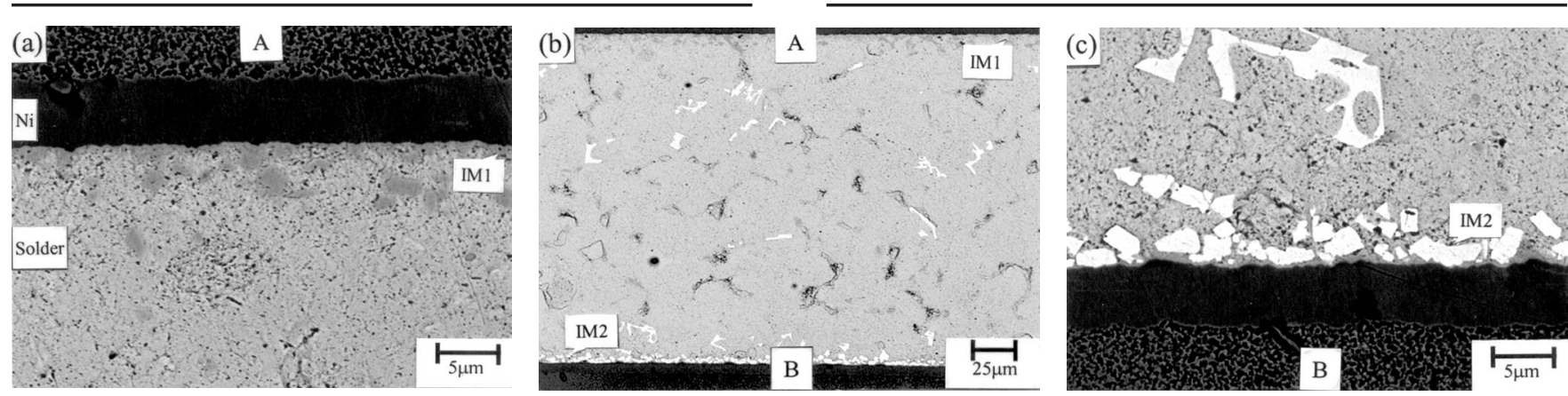

Fig. 6. Intermetallic compounds formed after the type 2 reflow process (one time): (b) a sandwich assembly. (a) and (c) Magnified images of the upper and lower sides of the assembly, respectively.
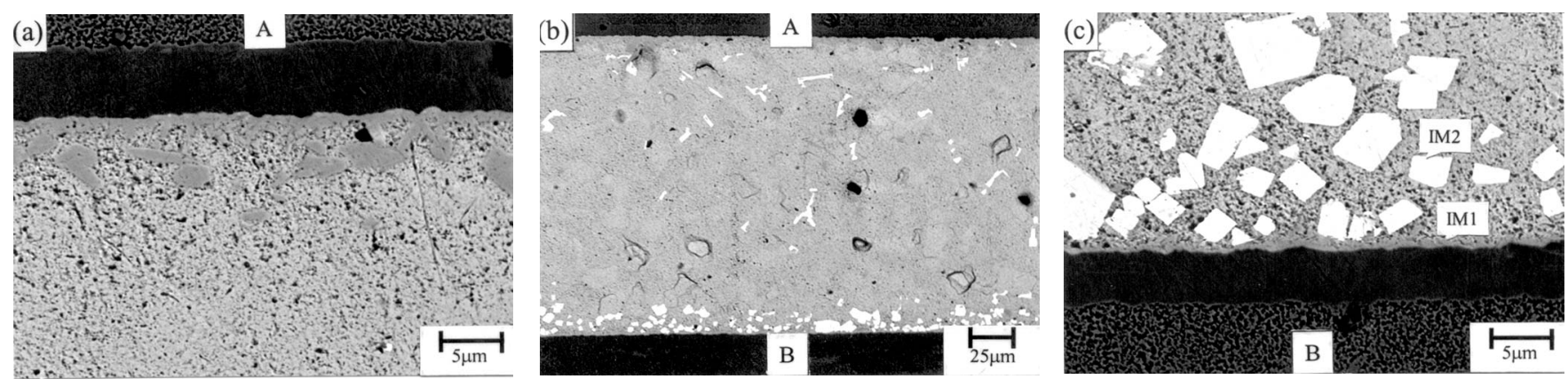

Fig. 7. Intermetallic compounds formed after the type 2 reflow process (two times): (b) a sandwich assembly. (a) and (c) Magnified images of the upper and lower sides of the assembly, respectively.

To summarize the results of the preceding series of experiments, the distribution of intermetallic compounds during the interfacial reactions between Sn$20 \mathrm{In}-0.8 \mathrm{Cu}$ solder balls and $\mathrm{Au} / \mathrm{Ni} / \mathrm{Cu}$ pads is not affected by the gravitational force as reported by Kim et al. on the soldering reactions of $\mathrm{Sn}-37 \mathrm{~Pb}$ with $\mathrm{Au} / \mathrm{Cu} / \mathrm{Cr}$ layers ${ }^{3}$ and Lee et al. ${ }^{4}$ on the reflowing of
$\mathrm{Sn} 3.5 \mathrm{Ag} / \mathrm{Cu}$ solder joints. A logical explanation for the selective formation of $\mathrm{Cu}_{6}(\mathrm{Sn}, \mathrm{In})_{5}$ intermetallics at specific interfaces is that the $\mathrm{Cu}_{6}(\mathrm{Sn}, \mathrm{In})_{5}$ intermetallics in the solder matrix tend to be attracted by the Ni layer of the $\mathrm{Au} / \mathrm{Ni}$ surface finish. Chen et al. have investigated the interfacial reactions between $\mathrm{Ni}$ substrates and a series of $\mathrm{Sn}-\mathrm{Cu}$ solders with 

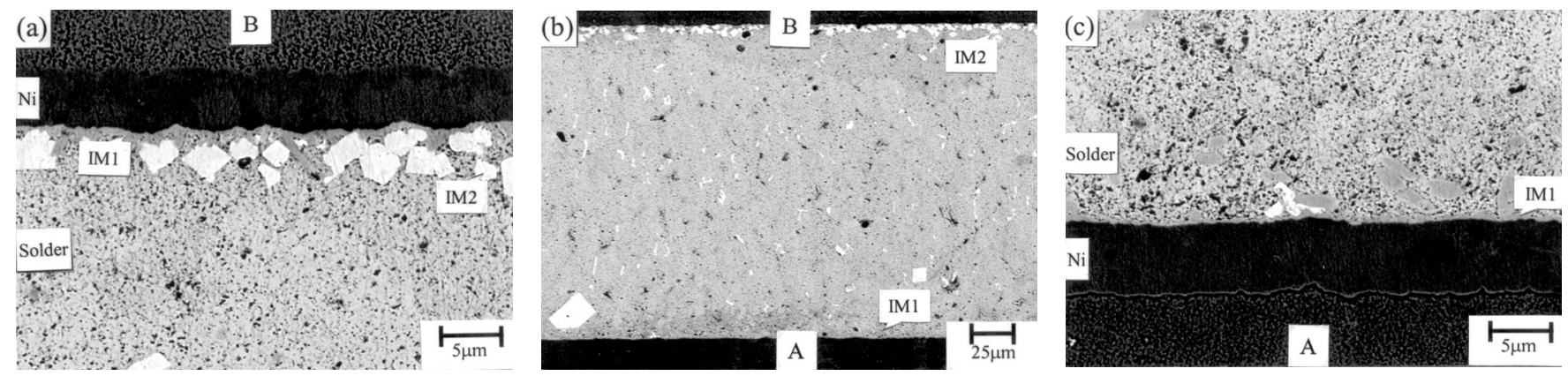

Fig. 8. Intermetallic compounds formed after the type 3 reflow process: (b) a sandwich assembly. (a) and (c) Magnified images of the upper and lower sides of the assembly, respectively.
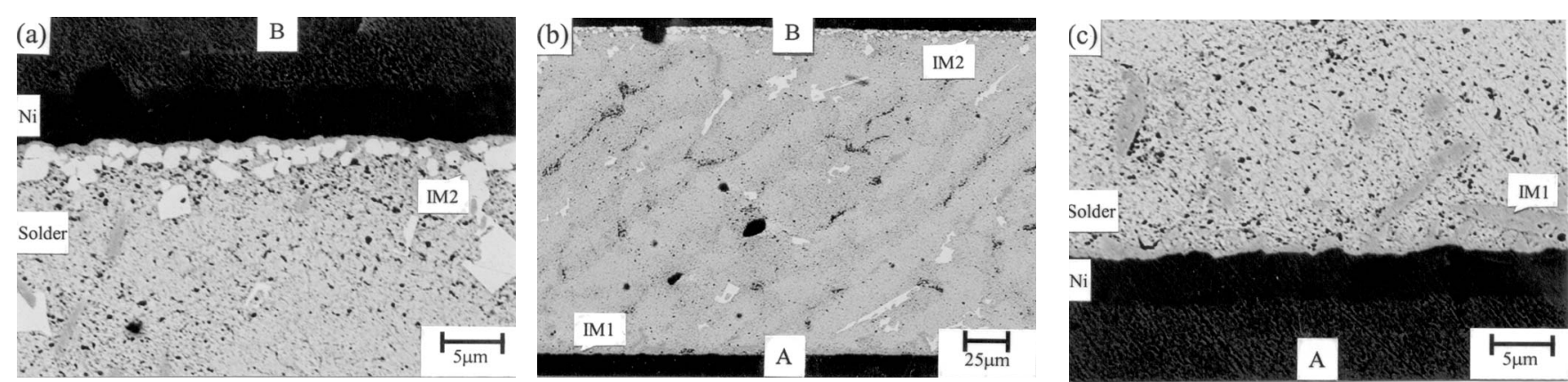

Fig. 9. Intermetallic compounds formed after the type 4 reflow process: (b) a sandwich assembly. (a) and (c) Magnified images of the upper and lower sides of the assembly, respectively.
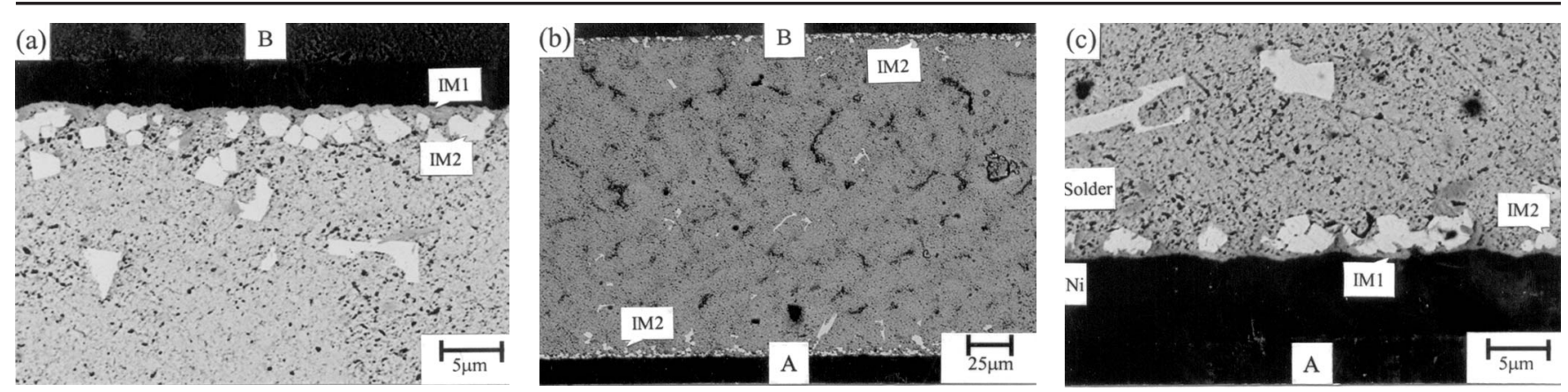

Fig. 10. Intermetallic compounds formed after primary reflowing of a Sn-20In-0.8Cu BGA solder package joined simultaneously with two substrates into (b) a sandwich assembly. (a) and (c) Magnified images of its upper and lower sides, respectively.
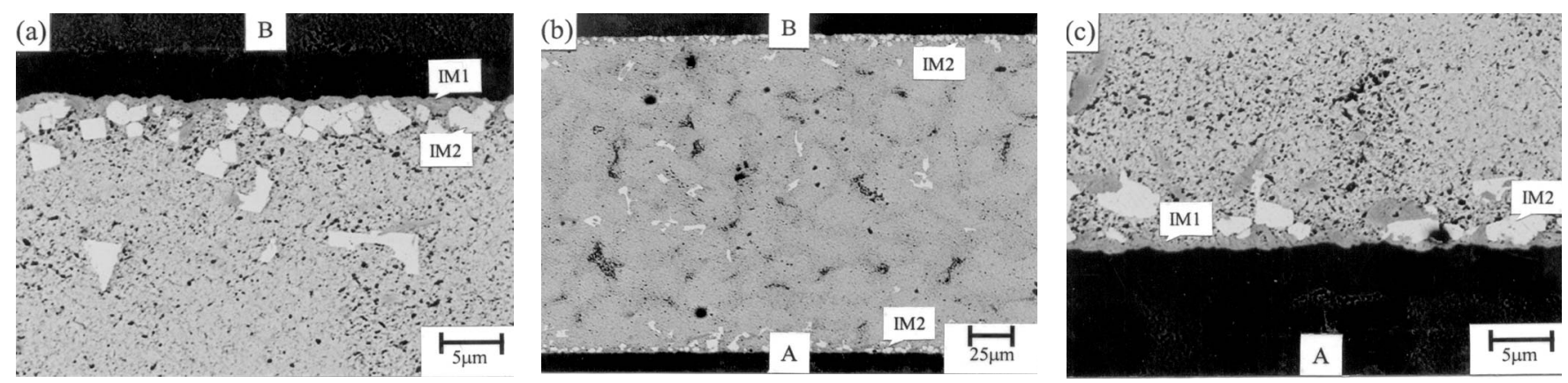

Fig. 11. Intermetallic compounds formed after secondary reflowing of a Sn-20In-0.8Cu BGA solder package joined simultaneously with two substrates into (b) a sandwich assembly. (a) and (c) Magnified images of its upper and lower sides, respectively.

various $\mathrm{Cu}$ contents. ${ }^{8}$ According to their report, at the $\mathrm{Ni} /$ solder interfaces $\left(\mathrm{Ni}_{1-\mathrm{x}} \mathrm{Cu}_{\mathrm{x}}\right)_{3} \mathrm{Sn}_{4}$ intermetallics appear when the $\mathrm{Cu}$ concentration in solders falls below 0.2 wt.\% while $\left(\mathrm{Cu}_{\mathrm{x}} \mathrm{Ni}_{1-\mathrm{x}}\right)_{6} \mathrm{Sn}_{5}$ intermetallics are found for the $\mathrm{Sn}-\mathrm{Cu}$ solders with high $\mathrm{Cu}$ content
$(\mathrm{Cu}=0.7-1$ wt.\% $)$. A moderate $\mathrm{Cu}$ concentration in $\mathrm{Sn}-\mathrm{Cu}$ solders $(0.4$ wt.\%) leads to the simultaneous formation of $\left(\mathrm{Ni}_{1-\mathrm{x}} \mathrm{Cu}_{\mathrm{x}}\right)_{3} \mathrm{Sn}_{4}$ and $\left(\mathrm{Cu}_{\mathrm{x}} \mathrm{Ni}_{1-\mathrm{x}}\right)_{6}$ $\mathrm{Sn}_{5}$ intermetallic compounds. Similar results have also been proposed by Jang et al. for the interfacial 
reactions of $\mathrm{Ni}-\mathrm{P} / \mathrm{Cu}$ under bump metallurgy with various solders. ${ }^{9}$ In the case of a Sn-3.5Ag solder, it is the $\mathrm{Ni}_{3} \mathrm{Sn}_{4}$ intermetallic phase generated at the interfaces. However, the ternary $\mathrm{Ni}_{4} \mathrm{Cu}_{7} \mathrm{Sn}_{6}$ intermetallic phase is found for $\mathrm{Sn}-0.7 \mathrm{Cu}$ and $\mathrm{Sn}-3.8 \mathrm{Ag}$ $0.7 \mathrm{Cu}$ solders. Furthermore, Liu and Wang have indicated that $\mathrm{Cu}$-Sn intermetallic compounds are preferentially formed near the Ni-Sn intermetallic layer on $\mathrm{Ni}$ pads by adding $\mathrm{Cu}$ particles into an Sn-3.5Ag solder bump. ${ }^{10}$ In another study of the soldering reactions of a $\mathrm{Ni} / \mathrm{Sn} 3.5 \mathrm{Ag} / \mathrm{Cu}$ sandwich structure, Wang and Liu also found that a $\mathrm{Cu}-\mathrm{Sn}$ intermetallic layer appeared at the interface of the Ni portion. ${ }^{11}$ They suggested that the formation of such $\mathrm{Cu}-\mathrm{Sn}$ intermetallics on the $\mathrm{Ni}$ substrate should be attributed to the reduction of $\mathrm{Cu}$ solubility in $\mathrm{Sn}$ caused by the presence of $\mathrm{Ni}$ atoms dissolved by dissolution from the $\mathrm{Ni}$ pad. The $\mathrm{Cu}$ concentration gradient in the solder matrix resulted in the $\mathrm{Cu}$ atomic fluxing toward the $\mathrm{Ni}$ substrate. In this present study, the $\mathrm{Cu}_{6}\left(\mathrm{Sn}_{0.87} \mathrm{Zn}_{0.17}\right)_{5}$ intermetallic compounds were generated at the $\mathrm{Ni} / \mathrm{Sn}-20 \mathrm{In}-0.8 \mathrm{Cu}$ interfaces by the similar driving force as proposed by Wang and $\mathrm{Liu}^{10,11}$ after the dissolution of the $\mathrm{Au}$ film on the $\mathrm{Au} / \mathrm{Ni}$ surface finishes. This driving force had played a dominant role to the effect that it could cause the gravitational sedimentation of intermetallic compounds in liquid solder. The formation of $\mathrm{Cu}_{6}\left(\mathrm{Sn}_{0.87} \mathrm{Zn}_{0.13}\right)_{5}$ prevented the appearance of $\mathrm{Au}\left(\mathrm{In}_{0.91} \mathrm{Sn}_{0.09}\right)_{2}$ intermetallics at the Ni/Sn-20In$0.8 \mathrm{Cu}$ interfaces.

When a sandwich assembly is created by attaching the primary reflowed assembly $\mathrm{A}$ further to another substrate (B), the formation of $\mathrm{Cu}_{6}\left(\mathrm{Sn}_{0.87} \mathrm{In}_{0.13}\right)_{5}$ intermetallics on the side of substrate $\mathrm{B}$ does not occur to the solder with lower $\mathrm{Cu}$ content. In this case, it is the dissolution of $\mathrm{Au}$ from the $\mathrm{Au} / \mathrm{Ni}$ surface finish that accounts for the preferential appearance of cubicshaped $\mathrm{Au}\left(\mathrm{In}_{0.91} \mathrm{Sn}_{0.09}\right)_{2}$ intermetallics at the interface of substrate $\mathrm{B}$. When the $\mathrm{Sn}-20 \mathrm{In}-0.8 \mathrm{Cu}$ solder balls are simultaneously joined with substrates $\mathrm{A}$ and $B$ to form a sandwich assembly, the $\mathrm{Cu}_{6}\left(\mathrm{Sn}_{0.87} \mathrm{In}_{0.13}\right)_{5}$ intermetallic compounds split into two parts that migrate toward substrates $\mathrm{A}$ and $\mathrm{B}$, respectively. In this case, the formation of $\mathrm{Cu}_{6}\left(\mathrm{Sn}_{0.87} \mathrm{In}_{0.13}\right)_{5}$ intermetallics at both solder/Ni interfaces is not enough to repel the $\mathrm{Au}\left(\mathrm{In}_{0.91} \mathrm{Sn}_{0.09}\right)_{2}$ intermetallics away from both substrates A and B, as observed in Figs. 10 and 11. The decrease in $\mathrm{Cu}$ content in the reacted solder matrix is attributed to the limited $\mathrm{Cu}$ supply adopted
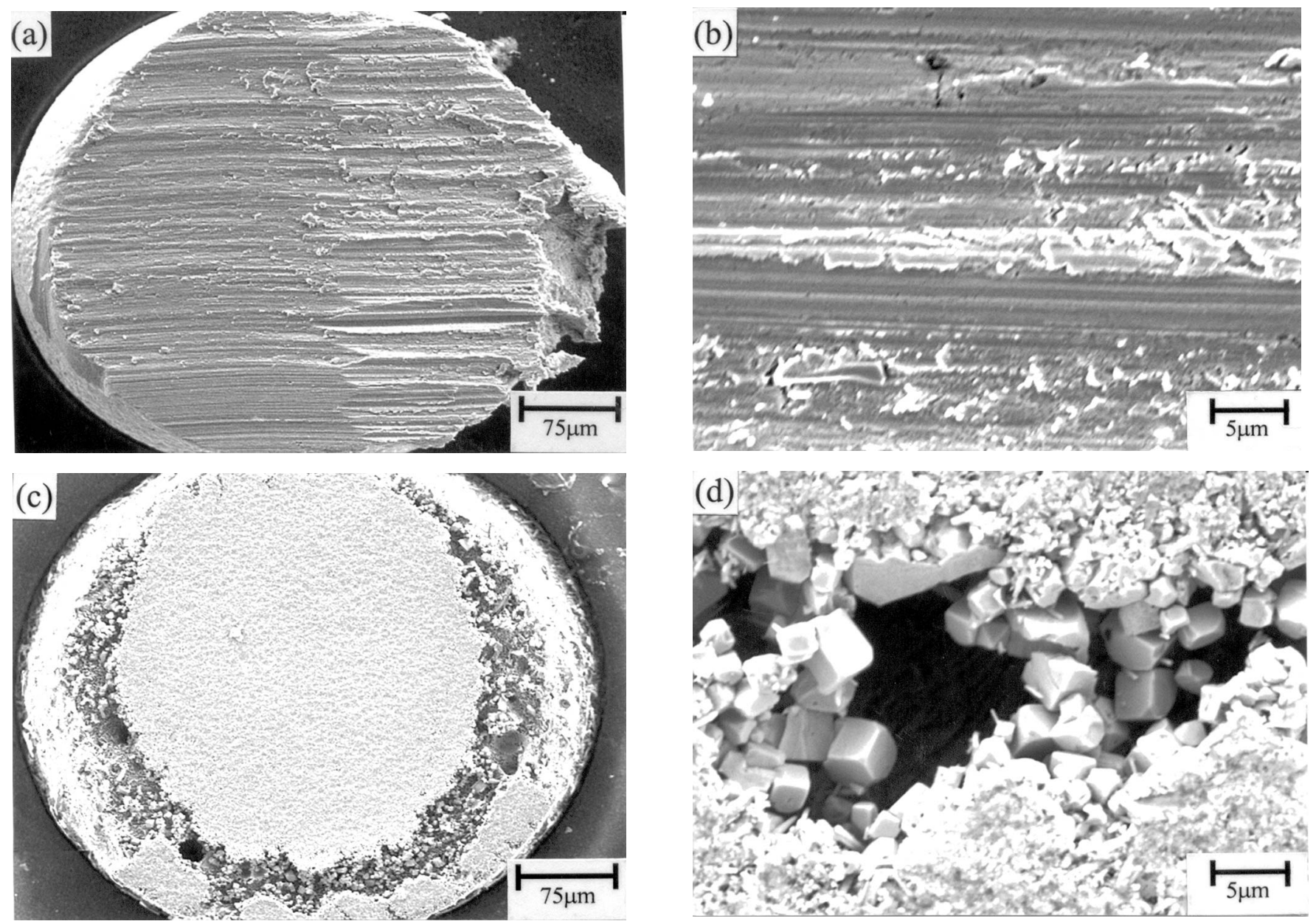

Fig. 12. (a) and (b) Fractography of the shear-tested specimen after type 1 reflowing (fracture shown on substrate A). (c) and (d) Fractography of the shear-tested specimen after type 2 reflowing (fracture shown on substrate B). 
by our experimental system, which is different from the study of Wang and Liu whose $\mathrm{Cu}$ resources include many $\mathrm{Cu}$ particles or a $\mathrm{Cu}$ plate. ${ }^{10,11}$

Shear tests are conducted on the solder joints after various types of reflow processes. From Fig. $12 \mathrm{a}$ and $\mathrm{b}$, the specimen after type 1 reflow shows a dimple fracture in the solder balls. In this case, the IM1P intermetallics with a mixed composition of $0.83\left[\mathrm{Cu}_{6}\left(\mathrm{Sn}_{0.87} \operatorname{In}_{0.13}\right)_{5}\right]+0.17\left[\mathrm{Ni}_{3}\left(\mathrm{Sn}_{0.87} \operatorname{In}_{0.13}\right)_{4}\right]$ have segregated at the solder/pad interfaces while the $\left(\mathrm{Au}_{0.80} \mathrm{Cu}_{0.20}\right)\left(\mathrm{In}_{0.33} \mathrm{Sn}_{0.67}\right)_{2}$ intermetallics are dispersed in the solder matrix. This result correlates well with the ball shear strengths in Fig. 5 as they too have shown no bearing on the growing of IM1P interfacial intermetallics with the increase of reflow cycles in the type 1 process. By contrast, all sandwich specimens (type 2-5 reflows) display brittle fractures on the substrate sides, which are accumulated with cubic-shaped $\mathrm{Au}\left(\mathrm{Sn}_{0.91} \mathrm{In}_{0.09}\right)_{2}$ intermetallics. Typical fractography of such cases is given in Fig. 12c and d. It is obvious that the predominant distribution of the $\mathrm{Au}\left(\operatorname{In}_{0.91} \mathrm{Sn}_{0.09}\right)_{2}$ interfacial intermetallics plays an important role in the bonding strength of the $\mathrm{Sn}-20 \mathrm{In}-0.8 \mathrm{Cu}$ solder in BGA packaging, yet it can be affected by the preferential formation of $\mathrm{Cu}_{6}\left(\mathrm{Sn}_{0.87} \mathrm{In}_{0.13}\right)_{5}$ intermetallics at the $\mathrm{Ni} / \mathrm{Sn}-20 \mathrm{In}-0.8 \mathrm{Cu}$ interfaces.

\section{CONCLUSIONS}

The selective formation of intermetallic compounds in $\mathrm{Sn}-20 \mathrm{In}-0.8 \mathrm{Cu}$ BGA solder joints with $\mathrm{Au} / \mathrm{Ni}$ surface finishes has been verified by performing various types of reflow processes. However, this study disagrees with the propositions of Kim et al. ${ }^{3}$ and Lee et al. ${ }^{4}$ regarding the effect of gravitational force on the asymmetric distribution of intermetallics in a solder joint. Here, the mechanism is proposed to be the preferential formation of $\mathrm{Cu}_{6}\left(\mathrm{Sn}_{0.87} \mathrm{In}_{0.13}\right)_{5}$ intermetallic compounds at the Ni/Sn-20In-0.8Cu interfaces after the dissolution of the $\mathrm{Au}$ film on $\mathrm{Au} / \mathrm{Ni}$ surface finishes. As plenty of the $\mathrm{Cu}_{6}\left(\mathrm{Sn}_{0.87} \operatorname{In}_{0.13}\right)_{5}$ intermetallic compounds have accumulated at the interface, the phenomenon can further inhibit the formation of $\mathrm{Au}\left(\mathrm{In}_{0.91} \mathrm{Sn}_{0.09}\right)_{2}$ intermetallics in the vicinity. Otherwise, such cubic-shaped $\mathrm{Au}\left(\mathrm{In}_{0.91} \mathrm{Sn}_{0.09}\right)_{2}$ intermetallic compounds will segregate near the solder/Ni interfaces and cause brittle fracture at the solder joints on that substrate.

\section{ACKNOWLEDGEMENTS}

The authors sincerely thank the National Science Council, Taiwan, for sponsoring this research under Grant No. NSC-91-2216-E002-037.

\section{REFERENCES}

1. M. Abtew and G. Selvaduray, Mater. Sci. Eng. 27, 95 (2000).

2. M.J. Chiang, S.Y. Chang, and T.H. Chuang, J. Electron. Mater. 33, 34 (2004).

3. H.K. Kim, K.N. Tu, and P.A. Totta, Appl. Phys. Lett. 68, 2204 (1996).

4. J.H. Lee, D.J. Park, J.N. Heo, Y.H. Lee, D.H. Shiu, and Y.S. Kim, Scripta Mater. 42, 827 (2000).

5. T.H. Chuang, S.Y. Chang, L.C. Tsao, W.P. Weng, and H.M. Wu, J. Electron. Mater. 32, 95 (2003).

6. I. Shohji, S. Fujiwara, S. Kiyono, and K.F. Kobayashi, Scripta Mater. 40, 815 (1999).

7. Y.M. Liu and T.H. Chuang, J. Electron. Mater. 29, 405 (2000).

8. W.T. Chen, R.Y. Tsai, Y.L. Lin, and C.R. Kao, J. SMT 15, 40 (2002).

9. J.W. Jang, D.R. Frear, T.Y. Lee, and K.N. Tu, J. Appl. Phys., 88,6359 (2000).

10. C.Y. Liu and S.J. Wang, J. Electron. Mater. 32, L1 (2003).

11. S.J. Wang and C.Y. Liu, J. Electron. Mater. 32, 1303 (2003). 